\title{
CROP PROTECTION
}

\section{Atratividade e Consumo Foliar por Adultos de Diabrotica speciosa (Germ.) (Coleoptera: Chrysomelidae) em Diferentes Genótipos de Abóbora}

\author{
EdSOn L.L. BALDin ${ }^{1}$ E Fernando M. LARA ${ }^{2}$ \\ ${ }^{1}$ Depto. Biologia, FFCLRP-USP, Av. Bandeirantes, 3900, 14040-901, Ribeirão Preto, SP \\ ${ }^{2}$ Depto. Fitossanidade, FCAV-UNESP, Via de Acesso Prof. Paulo Donato Castellane, s/n ${ }^{\circ}$ 14884-900, Jaboticabal, SP
}

Neotropical Entomology 30(4): 675-679 (2001)

\begin{abstract}
Attractiveness and Leaf Consumption by Adults of Diabrotica speciosa (Germ.) (Coleoptera: Chrysomelidae) in Different Squash Genotypes
\end{abstract}

\begin{abstract}
Some chrysomelids attack the squash from germination to harvest, destroying leaves and causing characteristical damage. Aiming to select squash genotypes less preferred by Diabrotica speciosa (Germar), assays with seedlings and leaf disks were performed at greenhouse and laboratory conditions. Initially, the attractiveness of thirty-three Cucurbita moschata genotypes and one C. maxima genotype (Exposição) was evaluated, the former used as a standard susceptible genotype. Free and no choice tests were performed with eight genotypes selected previously to evaluate seedlings and leaf disks consumption and attractiveness. The index of attractiveness indicated BRA003531 as the most attractive genotype, comparatively to the standard susceptible one. In free choice test for seedling consumption, BRA014869 was the genotype most preferred by adults of D. speciosa, although no significant differences with the control genotype were detected. BRA014958 was the most consumed genotype both in no choice test with seedlings and in free choice test with leaf disks; no choice tests with leaf discs, however, showed no differences on leaf consumption among the genotypes. All genotypes were as suscetible as the standard genotype, and the occurrence of non-preference for feeding as a resistance mechanism was not detected.
\end{abstract}

KEY WORDS: Insecta, Cucurbitaceae, feeding preference, host plant resistance.

RESUMO - Alguns crisomelídeos atacam a abóbora desde a germinação até a colheita, destruindo folhas e causando danos característicos. Com o objetivo de selecionar genótipos de abóbora menos preferidos para alimentação por Diabrotica speciosa (Germar), realizaram-se ensaios, em condições de casa-de-vegetação e de laboratório, utilizando-se plântulas e discos foliares. Inicialmente avaliouse a atratividade de 33 genótipos de abóbora Cucurbita moschata e um genótipo comercial de moranga C. maxima (Exposição), utilizado como genótipo suscetível padrão. Visando observar o consumo realizado em plântulas, efetuaram-se testes com e sem chance de escolha com oito genótipos selecionados a partir do ensaio de atratividade. Em placas de Petri, foram realizados testes de atratividade e consumo, com e sem chance de escolha, utilizando-se discos foliares de oito materiais. O índice de atratividade apontou o genótipo BRA003531 como o mais atrativo em relação ao padrão comercial (genótipo Exposição). Em teste de consumo com chance de escolha, utilizando-se plântulas, o genótipo BRA014869 foi o mais preferido para alimentação por adultos de D. speciosa, embora somente diferisse estatísticamente do genótipo BRA015059. BRA014958 revelou-se o mais consumido em teste sem chance de escolha com plântulas e em teste com chance de escolha utilizando-se discos foliares; em testes com discos foliares sem escolha, entretanto não se observaram diferenças entre os genótipos. Em geral todos os genótipos revelaram-se igualmente suscetíveis ao padrão Exposição, não tendo sido detectada a ocorrência de resistência do tipo não-preferência para alimentação.

PALAVRAS-CHAVE: Insecta, Cucurbitaceae, preferência alimentar, resistência de plantas. 
Dentre as pragas das cucurbitáceas, a vaquinha Diabrotica speciosa (Germ.) assume grande importância econômica, por danificar as plantas desde sua germinação até a época de colheita dos frutos. Os adultos consomem as folhas da abóbora, abobrinha, moranga e melancia, deixando orifícios típicos de seu ataque, além de atuarem como vetores de algumas viroses nestas culturas (Barbosa \& França 1982, Boff \& Gandin 1992). Segundo Dhillon \& Wehner (1991), as vaquinhas são as pragas mais importantes das cucurbitáceas e quando atacam as plântulas, podem causar sua morte. No Brasil não existem dados qualitativos e quantitativos dos prejuízos que esse inseto tem causado às lavouras (Milanez \& Parra 2000).

Para o controle de D. speciosa utilizam-se diversos métodos de controle, tais como a rotação de culturas, o controle biológico, o controle químico e variedades resistentes. Este último método é o mais desejável porque, além de gratuito para o agricultor, não é poluente nem causa desequilíbrio biológico (Rossetto et al. 1981, Lara 1991). Além de não interferir com outras práticas agrícolas, permite boa eficiência de controle em níveis baixos da população do inseto. Com o objetivo de selecionar genótipos de abóbora menos preferidos por D. speciosa, foram realizados testes de atratividade e de consumo alimentar, utilizando-se plântulas e discos foliares de diferentes genótipos, em condições de casa-de-vegetação e de laboratório.

\section{Material e Métodos}

A atração e a preferência alimentar de adultos de $D$. speciosa por plântulas e discos foliares de diferentes genótipos de abóbora ( $C$. moschata) e moranga (C. maxima) foram estudadas em condições de casa-de-vegetação e de laboratório no Departamento de Fitossanidade, da Faculdade de Ciências Agrárias e Veterinárias, UNESP, Jaboticabal, durante o ano de 1999. Para a realização dos ensaios, os insetos foram coletados em plantações de milho e alfafa e mantidos sem alimento por $24 \mathrm{~h}$ antes do início dos testes.

Ensaios com Plântulas. Em casa-de-vegetação realizouse um teste de atratividade com plântulas (15 dias de idade) de 33 genótipos de abóbora C. moschata (BRA003531, BRA003433, BRA014737, BRA015156, BRA015008, BRA013714, BRA014958, BRA014923, BRA014893, BRA003662, BRA015105, BRA003671, BRA015032, BRA014711, BRA014702, BRA015016, BRA014991, BRA015113, BRA014940, BRA014669, BRA003638, BRA014672, BRA014770, BRA003603, BRA014681, BRA014788, BRA015024, BRA014869, BRA015059, BRA014915, BRA014664, BRA014745, BRA014834). Utilizou-se o genótipo comercial de moranga $C$. maxima (Exposição), que apresenta elevada suscetibilidade, como padrão no cálculo do índice de atratividade. Os materiais foram semeados em copos plásticos de $200 \mathrm{ml}$ e, após a emergência dos cotilédones, acondicionados no interior de gaiolas $(1,5 \times 0,50 \times 0,50 \mathrm{~m})$ revestidas com tela. Ao centro das gaiolas liberaram-se cinco indivíduos/genótipo, avaliando-se o número de insetos atraídos por material 30 , 75 e 120 min. após a liberação. Utilizou-se o delineamento inteiramente casualizado com quatro repetições.
Calculou-se o índice de atratividade do inseto utilizandose a seguinte fórmula: $I A=2 G /(G+P)$, onde $I A=$ índice de atratividade; $\mathrm{G}=$ número de insetos atraídos para o genótipo avaliado e $\mathrm{P}=$ número de insetos atraídos para o genótipo padrão (Lin et al. 1990). Os valores de IA variam entre zero e dois, sendo que $I A=1$ indica atração semelhante entre o genótipo avaliado e o padrão, $\mathrm{IA}>1$ indica maior atração pelo genótipo avaliado em relação ao padrão e IA $<1$ corresponde a menor atração. Os materiais foram classificados comparando-se o índice obtido no genótipo avaliado com o do genótipo padrão, adotando-se o erro padrão (EP) para diferenciação dos mesmos. Com base nos índices de atratividade obtidos e na disponibilidade de sementes de cada material, selecionaram-se oito genótipos, sendo quatro pouco atrativos (BRA014745, BRA015059, BRA014869 e BRA015024), três muito atrativos (BRA003531, BRA014737 e BRA014958), juntamente com o padrão comercial (Exposição) para os testes de consumo com e sem chance de escolha, em laboratório.

No teste com chance de escolha, os genótipos foram semeados em copos plástico (café) e colocados no interior de gaiolas de vidro ( $30 \times 30 \times 40 \mathrm{~cm}$ ), cobertas com tecido voil, liberando-se, em seguida, os adultos de $D$. speciosa na proporção de oito insetos por genótipo, em 10 repetições, seguindo o delineamento inteiramente casualizado. $\mathrm{O}$ consumo foliar foi avaliado atribuindo-se notas, utilizandose a escala visual proposta por Lara et al. (1999), em que: nenhum consumo $=1 ; 1$ a $25 \%=2 ; 26$ a $50 \%=3 ; 51$ a $75 \%$ $=4$ e 76 a $100 \%=5$. O teste era imediatamente encerrado quando um dos materiais apresentava cerca de $80 \%$ dos cotilédones consumidos. Para o teste sem chance de escolha, realizaram-se cinco repetições, seguindo-se a mesma metodologia de avaliação e delineamento estatístico empregados no teste com chance de escolha, porém os genótipos foram colocados isoladamente dentro de gaiolas de vidro menores $(20 \times 20 \times 20 \mathrm{~cm})$.

Ensaios com Discos Foliares. Realizaram-se testes de atratividade e consumo, utilizando-se discos foliares $\left(3,54 \mathrm{~cm}^{2}\right)$ dos oito genótipos selecionados para os testes de consumo com plântulas. Os discos foliares foram extraídos de folhas verdadeiras, com o auxílio de um vazador metálico. No teste com chance de escolha, os discos foram colocados no interior de placas de Petri, forradas com papel de filtro umedecido. Dois insetos/disco foram liberados e, após $2 \mathrm{~h}$, através da contagem do número de insetos pousados sobre os discos, avaliou-se a atratividade nos genótipos. Utilizou-se o delineamento de blocos casualizados com dez repetições. Em teste sem chance de escolha manteve-se o mesmo esquema de avaliações, porém os discos foram colocados individualmente no interior de placas de Petri, juntamente com dois insetos/placa; realizaram-se dez repetições em delineamento inteiramente casualizado. $\mathrm{O}$ consumo nos discos foliares foi determinado com auxílio de um medidor de área foliar (LI-COR 3000A).

Análise Estatística. Os dados de atratividade e de consumo foliar foram submetidos a análise de variância, sendo as médias comparadas pelo teste de Tukey, ao nível de 5\% de probabilidade. Quando necessário, os dados originais (x) foram transformados para $(x+0,5)^{1 / 2}$. 


\section{Resultados e Discussão}

Ensaios com Plântulas. As plântulas do genótipo BRA003531 apresentaram índice médio de atratividade superior a 1 nos três períodos de avaliação, sendo classificadas como mais atrativas que as do genótipo padrão, Exposição (Tabela 1). Outros genótipos que também se destacaram como mais atrativos que o genótipo padrão foram BRA003433 aos $30 \mathrm{~min}$., BRA014737 aos $120 \mathrm{~min}$. e BRA014958 aos 75 e 120 min. após a liberação dos insetos. Os demais materiais apresentaram índices próximos ou inferiores a 1 , sendo classificados como neutros ou menos atrativos, respectivamente, em relação ao padrão, segundo a interpretação proposta por Lin et al. (1990).

Tabela 1. Índice de atratividade e classificação de plântulas de abóbora quanto à preferência por adultos de $D$. speciosa em diferentes períodos de observação.

\begin{tabular}{|c|c|c|c|c|c|c|}
\hline \multirow{3}{*}{ Genótipos } & \multicolumn{6}{|c|}{ Índice de atratividade $^{1}$} \\
\hline & \multicolumn{2}{|c|}{$30 \mathrm{~min}}$. & \multicolumn{2}{|c|}{75 min. } & \multicolumn{2}{|c|}{$120 \mathrm{~min}}$. \\
\hline & $\mathrm{M}( \pm \mathrm{EP})$ & Classif. $^{2}$ & $\mathrm{M}( \pm \mathrm{EP})$ & Classif. $^{2}$ & $\mathrm{M}( \pm \mathrm{EP})$ & Classif. $^{2}$ \\
\hline BRA003531 & $1,47 \pm 0,28$ & + & $1,30 \pm 0,25$ & + & $1,29 \pm 0,24$ & + \\
\hline BRA003433 & $1,34 \pm 0,28$ & + & $1,16 \pm 0,25$ & $\mathrm{~N}$ & $1,14 \pm 0,24$ & $\mathrm{~N}$ \\
\hline BRA014737 & $1,23 \pm 0,28$ & $\mathrm{~N}$ & $1,24 \pm 0,25$ & $\mathrm{~N}$ & $1,26 \pm 0,24$ & + \\
\hline BRA015156 & $1,13 \pm 0,28$ & $\mathrm{~N}$ & $1,03 \pm 0,25$ & $\mathrm{~N}$ & $0,99 \pm 0,24$ & $\mathrm{~N}$ \\
\hline BRA013714 & $1,04 \pm 0,28$ & $\mathrm{~N}$ & $0,92 \pm 0,25$ & $\mathrm{~N}$ & $0,74 \pm 0,24$ & - \\
\hline BRA015008 & $1,00 \pm 0,28$ & $\mathrm{~N}$ & $0,83 \pm 0,25$ & $\mathrm{~N}$ & $0,78 \pm 0,24$ & $\mathrm{~N}$ \\
\hline Exposição & $1,00 \pm 0,28$ & Padrão & $1,00 \pm 0,25$ & Padrão & $1,00 \pm 0,24$ & Padrão \\
\hline BRA014958 & $0,99 \pm 0,28$ & $\mathrm{~N}$ & $1,31 \pm 0,25$ & + & $1,30 \pm 0,24$ & + \\
\hline BRA014893 & $0,93 \pm 0,28$ & $\mathrm{~N}$ & $0,93 \pm 0,25$ & $\mathrm{~N}$ & $0,91 \pm 0,24$ & $\mathrm{~N}$ \\
\hline BRA015105 & $0,88 \pm 0,28$ & $\mathrm{~N}$ & $0,91 \pm 0,25$ & $\mathrm{~N}$ & $0,87 \pm 0,24$ & $\mathrm{~N}$ \\
\hline BRA014923 & $0,88 \pm 0,28$ & $\mathrm{~N}$ & $0,97 \pm 0,25$ & $\mathrm{~N}$ & $0,84 \pm 0,24$ & $\mathrm{~N}$ \\
\hline BRA003671 & $0,84 \pm 0,28$ & $\mathrm{~N}$ & $0,85 \pm 0,25$ & $\mathrm{~N}$ & $0,88 \pm 0,24$ & $\mathrm{~N}$ \\
\hline BRA003662 & $0,83 \pm 0,28$ & $\mathrm{~N}$ & $0,89 \pm 0,25$ & $\mathrm{~N}$ & $0,89 \pm 0,24$ & $\mathrm{~N}$ \\
\hline BRA015032 & $0,79 \pm 0,28$ & $\mathrm{~N}$ & $0,95 \pm 0,25$ & $\mathrm{~N}$ & $0,99 \pm 0,24$ & $\mathrm{~N}$ \\
\hline BRA015016 & $0,78 \pm 0,28$ & $\mathrm{~N}$ & $0,92 \pm 0,25$ & $\mathrm{~N}$ & $0,92 \pm 0,24$ & $\mathrm{~N}$ \\
\hline BRA014711 & $0,71 \pm 0,28$ & - & $0,59 \pm 0,25$ & - & $0,59 \pm 0,24$ & - \\
\hline BRA014702 & $0,68 \pm 0,28$ & - & $0,68 \pm 0,25$ & - & $0,83 \pm 0,24$ & $\mathrm{~N}$ \\
\hline BRA014991 & $0,59 \pm 0,28$ & - & $0,62 \pm 0,25$ & - & $0,57 \pm 0,24$ & - \\
\hline BRA015113 & $0,58 \pm 0,28$ & - & $0,50 \pm 0,25$ & - & $0,71 \pm 0,24$ & - \\
\hline BRA014940 & $0,58 \pm 0,28$ & - & $1,03 \pm 0,25$ & - & $0,91 \pm 0,24$ & $\mathrm{~N}$ \\
\hline BRA014669 & $0,50 \pm 0,28$ & - & $0,43 \pm 0,25$ & - & $0,43 \pm 0,24$ & - \\
\hline BRA014672 & $0,48 \pm 0,28$ & - & $0,54 \pm 0,25$ & - & $0,77 \pm 0,24$ & $\mathrm{~N}$ \\
\hline BRA003638 & $0,48 \pm 0,28$ & - & $0,23 \pm 0,25$ & - & $0,51 \pm 0,24$ & - \\
\hline BRA014770 & $0,43 \pm 0,28$ & - & $0,62 \pm 0,25$ & - & $0,74 \pm 0,24$ & - \\
\hline BRA003603 & $0,40 \pm 0,28$ & - & $0,43 \pm 0,25$ & - & $0,47 \pm 0,24$ & - \\
\hline BRA014681 & $0,38 \pm 0,28$ & - & $0,76 \pm 0,25$ & $\mathrm{~N}$ & $0,83 \pm 0,24$ & $\mathrm{~N}$ \\
\hline BRA015024 & $0,33 \pm 0,28$ & - & $0,30 \pm 0,25$ & - & $0,25 \pm 0,24$ & - \\
\hline BRA014788 & $0,32 \pm 0,28$ & - & $0,32 \pm 0,25$ & - & $0,37 \pm 0,24$ & - \\
\hline BRA014869 & $0,25 \pm 0,28$ & - & $0,50 \pm 0,25$ & - & $0,48 \pm 0,24$ & - \\
\hline BRA015059 & $0,25 \pm 0,28$ & - & $0,54 \pm 0,25$ & - & $0,58 \pm 0,24$ & - \\
\hline BRA014664 & $0,20 \pm 0,28$ & - & $0,33 \pm 0,25$ & - & $0,33 \pm 0,24$ & - \\
\hline BRA014915 & $0,20 \pm 0,28$ & - & $0,77 \pm 0,25$ & $\mathrm{~N}$ & $0,72 \pm 0,24$ & - \\
\hline BRA014745 & $0,17 \pm 0,28$ & - & $0,42 \pm 0,25$ & - & $0,29 \pm 0,24$ & - \\
\hline BRA014834 & $0,10 \pm 0,28$ & - & $0,47 \pm 0,25$ & - & $0,34 \pm 0,24$ & - \\
\hline
\end{tabular}

${ }^{1} \mathrm{IA}=2 \mathrm{G} / \mathrm{G}+\mathrm{P}\left(\mathrm{G}=\mathrm{n}^{\mathrm{o}}\right.$ de insetos no genótipo avaliado; $\mathrm{P}=\mathrm{n}^{\mathrm{o}}$ de insetos no genótipo padrão $)$.

${ }^{2}$ Classificação dos materiais, onde $(+)=$ mais atrativo que o padrão, $(-)=$ menos atrativo que o padrão e $(\mathrm{N})=$ neutro ou semelhante em relação ao padrão. 
Em condições de livre escolha, as plântulas do genótipo BRA014869 foram as mais consumidas por adultos de $D$. speciosa (Tabela 2), não diferindo do padrão Exposição, mas diferindo significativamente de BRA015059, que se destacou como o genótipo menos consumido; nas plântulas dos demais genótipos o consumo foliar foi intermediário. Em teste sem chance de escolha, o genótipo BRA014958 foi o mais preferido para alimentação, diferindo significativamente de BRA014737, BRA015024, Exposição, BRA003531 e BRA015059, mas não de BRA014745 e BRA014869.

O genótipo BRA014869, embora pouco atrativo (Tabela 1), foi o mais consumido em teste com chance de escolha. Esse comportamento, segundo Beck (1965), indica que mesmo contendo poucos compostos atraentes, um genótipo pode conter estimulantes para a alimentação do inseto. Ao contrário, BRA003531 revelou-se muito atrativo, porém foi pouco consumido, indicando a presença de substâncias deterrentes.

Tabela 2. Notas de consumo médio ( \pm EP) de adultos de $D$. speciosa em plântulas de genótipos de abóbora. $\mathrm{T}=25 \pm 2{ }^{\circ} \mathrm{C}, \mathrm{UR}=65 \pm 10 \%$.

\begin{tabular}{lcc}
\hline \multirow{2}{*}{ Genótipos } & \multicolumn{2}{c}{ Nota de consumo $^{1}$} \\
\cline { 2 - 3 } & $\begin{array}{c}\text { Com chance de } \\
\text { escolha }\end{array}$ & $\begin{array}{c}\text { Sem chance de } \\
\text { escolha }\end{array}$ \\
\hline BRA014869 & $3,5 \pm 0,45 \mathrm{a}$ & $2,8 \pm 0,37 \mathrm{ab}$ \\
BRA014737 & $3,1 \pm 0,46 \mathrm{ab}$ & $2,6 \pm 0,40 \mathrm{~b}$ \\
BRA014958 & $3,1 \pm 0,43 \mathrm{ab}$ & $4,0 \pm 0,32 \mathrm{a}$ \\
BRA014745 & $2,5 \pm 0,22 \mathrm{ab}$ & $3,0 \pm 0,32 \mathrm{ab}$ \\
BRA015024 & $2,4 \pm 0,40 \mathrm{ab}$ & $2,6 \pm 0,24 \mathrm{~b}$ \\
Exposição & $2,4 \pm 0,22 \mathrm{ab}$ & $2,2 \pm 0,20 \mathrm{~b}$ \\
BRA003531 & $2,2 \pm 0,25 \mathrm{ab}$ & $2,4 \pm 0,24 \mathrm{~b}$ \\
BRA015059 & $1,9 \pm 0,18 \mathrm{~b}$ & $2,6 \pm 0,24 \mathrm{~b}$ \\
\hline F & $2,44^{*}$ & $3,36^{*}$ \\
CV (\%) & 41,66 & 24,17 \\
\hline
\end{tabular}

${ }^{1}$ Nota de consumo avaliada segundo escala visual (Nota $1=$ nenhum dano; Nota $2=1$ a $25 \%$ de dano; Nota $3=26$ a 50\% de dano; Nota $4=51$ a $75 \%$ de dano e Nota $5=76$ a $100 \%$ de dano).

Médias seguidas de mesma letra não diferem estatisticamente pelo teste de Tukey ao nível de 5\% de probabilidade.

Ensaios com Discos Foliares. Com relação à atração dos insetos por discos foliares dos genótipos de abóbora (Fig. 1), não se observou diferença estatística entre os materiais testados. Porém com relação à área foliar consumida em discos foliares (Tabela 3 ), nota-se que, em teste com chance de escolha, o genótipo BRA014958 foi o mais consumido, diferindo significativamente de todos os materiais testados. Em teste sem chance de escolha, não se constataram diferenças estatísticas quanto ao consumo foliar nos materiais.

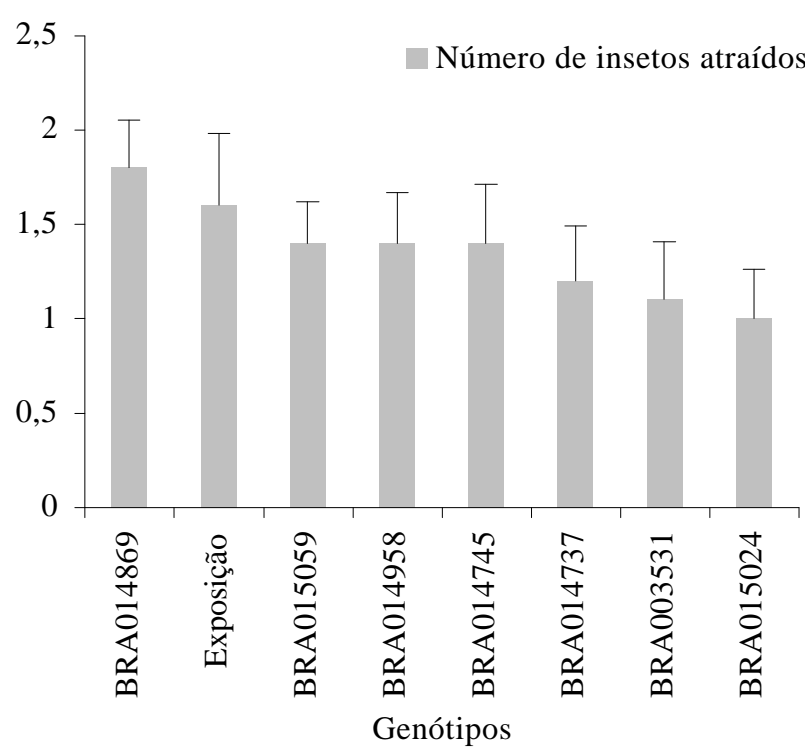

Figura 1. Número médio ( $\pm \mathrm{EP})$ de adultos de $D$. speciosa atraídos por discos foliares de genótipos de abóbora, após $2 \mathrm{~h}$ da liberação. $\mathrm{T}=25 \pm 2^{\circ} \mathrm{C} ; \mathrm{UR}=65 \pm 10 \%$. Não se observou diferença estatística pelo teste de Tukey ao nível de 5\% de probabilidade.

As diferenças observadas entre alguns genótipos e o padrão suscetível quanto à atratividade de plântulas (Tabela 1) poderia indicar a ocorrência de não-preferência para alimentação como mecanismo de resistência atuante, entretanto o contraste entre os materiais não foi mantido no teste de consumo (Tabela 2) e nos testes com discos foliares

Tabela 3. Médias $( \pm E P)$ de área foliar consumida por adultos de $D$. speciosa em diferentes genótipos de abóbora. $\mathrm{T}=25 \pm 2^{\circ} \mathrm{C}$, U.R. $=65 \pm 10 \%$.

\begin{tabular}{lcc}
\hline \multirow{2}{*}{ Genótipos } & \multicolumn{2}{c}{ Área foliar consumida $\left(\mathrm{cm}^{2}\right)$} \\
\cline { 2 - 3 } & $\begin{array}{c}\text { Com chance de } \\
\text { escolha }\end{array}$ & $\begin{array}{c}\text { Sem chance de } \\
\text { escolha }\end{array}$ \\
\hline BRA014958 & $1,07 \pm 0,31 \mathrm{a}$ & $1,22 \pm 0,14 \mathrm{a}$ \\
BRA014869 & $0,43 \pm 0,14 \mathrm{~b}$ & $1,22 \pm 0,14 \mathrm{a}$ \\
Exposição & $0,36 \pm 0,11 \mathrm{~b}$ & $0,87 \pm 0,19 \mathrm{a}$ \\
BRA014745 & $0,21 \pm 0,05 \mathrm{~b}$ & $1,22 \pm 0,10 \mathrm{a}$ \\
BRA014737 & $0,19 \pm 0,06 \mathrm{~b}$ & $0,77 \pm 0,13 \mathrm{a}$ \\
BRA015059 & $0,16 \pm 0,05 \mathrm{~b}$ & $1,05 \pm 0,11 \mathrm{a}$ \\
BRA003531 & $0,15 \pm 0,07 \mathrm{~b}$ & $0,68 \pm 0,12 \mathrm{a}$ \\
BRA015024 & $0,14 \pm 0,05 \mathrm{~b}$ & $0,66 \pm 0,11 \mathrm{a}$ \\
\hline F & $5,61^{*}$ & $3,54^{*}$ \\
CV (\%) & 20,56 & 15,04 \\
\hline
\end{tabular}

Médias seguidas de mesma letra não diferem estatisticamente pelo teste de Tukey ao nível de $5 \%$ de probabilidade. Dados originais (x) foram transformados para $(x+0,5)^{1 / 2}$. 
(Tabela 3 e Fig. 1). Uma comparação geral entre os materiais testados e o padrão Exposição ao longo dos ensaios indica que todos os genótipos são igualmente suscetíveis ao ataque de D. speciosa.

Por outro lado, como trata-se de genótipos de abóbora ainda não comerciais, os materiais requerem novos estudos, principalmente a campo, a fim de confirmar os resultados obtidos neste trabalho.

\section{Agradecimentos}

À FAPESP, pela Bolsa de Doutorado concedida ao primeiro autor, ao Conselho Nacional de Desenvolvimento Científico e Tecnológico - CNPq, pela Bolsa de Produtividade em Pesquisa concedida ao segundo autor e à Dra. Maria de Fátima Batista (EMBRAPA/CENARGEN) pelo fornecimento das sementes de abóbora utilizadas no trabalho.

\section{Literatura Citada}

Barbosa, S. \& F.H. França. 1982. Pragas das cucurbitáceas e seu controle. Inf. Agropec. 8: 54-56.

Beck, S.D. 1965. Resistance of plants to insects. Ann. Rev. Entomol. 10: 207-232.

Boff, M.I.C. \& C.L. Gandin. 1992. Principais pragas na cultura da melancia e seu controle. Agrop. Catarinense 5: 39-41.
Dhillon, N.P.S. \& T.C. Wehner. 1991. Host-plant resistance to insects in cucurbits-germoplasm resources, genetics and breeding. Trop. Pest. Manag. 37: 421-428.

Lara, F.M. 1991. Princípios de resistência de plantas a insetos. 2.ed., São Paulo, Ícone, 336p.

Lara, F.M., J.M. Elias, E.L.L. Baldin \& J.C. Barbosa. 1999. Preferência alimentar de Diabrotica speciosa (Germ.) e Cerotoma sp. por genótipos de soja. Sci. Agric. 56: 947-951.

Lin, H., M. Kogan \& D. Fischer. 1990. Induced resistance in soybean to the mexican bean beetle (Coleoptera: Coccinelidae): comparisons of inducing factors. Environ. Entomol. 19: 1852-1857.

Milanez, J.M. \& J.R.P. Parra. 2000. Preferência de Diabrotica speciosa (Germar) (Coleoptera: Chrysomelidae) para oviposição em diferentes tipos e umidades de solo. An. Soc. Entomol. Brasil 29: 155158 .

Rossetto, C.J., V. Nagai, T. Igue, D. Rossetto \& M.A.C. Miranda. 1981. Preferência de alimentação de adultos de Diabrotica speciosa (Germar) e Cerotoma arcuata (Oliv.) em variedades de soja. Bragantia 40: 179-183.

Received 27/06/00. Accepted 30/09/01. 